\title{
Framework for Risk-Based Decision Support on Infiltration and Inflow to Wastewater Systems
}

\author{
Anna Ohlin Saletti ${ }^{1,2, *}$, Lars Rosén ${ }^{1}$ and Andreas Lindhe ${ }^{1}$ (D) \\ 1 Department of Architecture and Civil Engineering, Chalmers University of Technology, \\ 41296 Gothenburg, Sweden; lars.rosen@chalmers.se (L.R.); andreas.lindhe@chalmers.se (A.L.) \\ 2 Department of Sustainable Waste and Water, City of Gothenburg, 41502 Gothenburg, Sweden \\ * Correspondence: anna.ohlin.saletti@chalmers.se; Tel.: +46-73-529-1519
}

Citation: Ohlin Saletti, A.; Rosén, L.; Lindhe, A. Framework for Risk-Based Decision Support on Infiltration and Inflow to Wastewater Systems. Water 2021, 13, 2320. https://doi.org/ $10.3390 / w 13172320$

Academic Editor: Yurui Fan

Received: 24 June 2021

Accepted: 20 August 2021

Published: 25 August 2021

Publisher's Note: MDPI stays neutral with regard to jurisdictional claims in published maps and institutional affiliations.

Copyright: (c) 2021 by the authors. Licensee MDPI, Basel, Switzerland. This article is an open access article distributed under the terms and conditions of the Creative Commons Attribution (CC BY) license (https:// creativecommons.org/licenses/by/ $4.0 /)$.

\begin{abstract}
Infiltration and inflow (I/I) to wastewater systems cause e.g., flooding, pollution, and the unnecessary use of the limited resources in society. Due to climate change and an increased need for the renewal of piping systems, making the right decisions on how to handle I/I is more important than ever. This paper presents a novel framework for risk-based decision support on I/I based on established theories on risk assessment and decision-making. The framework is presented on a general level and suggests that uncertainties are included in the decision-making process, together with criteria representing the economic, social, and environmental dimensions of sustainability. Published models on I/I and decision support are evaluated based on criteria from the framework showing that (1) the models rarely include risk-based decision-making or uncertainties in the analyses and that (2) most models only include project-internal financial aspects, excluding social and environmental, as well as project-external aspects, of I/I and I/I measures. A need for further research to develop a more holistic decision support model for I/I is identified, and it is concluded that the application of the proposed framework can contribute to more sustainable decisions on how to handle I/I and provide transparency to the process.
\end{abstract}

Keywords: infiltration; inflow; I/I; wastewater; decision support; risk assessment

\section{Introduction}

Wastewater systems transport and treat wastewater to protect our cities, public health, and the environment. Apart from sanitary sewage, the wastewater system contains infiltration and inflow water (I/I-water). I/I-water can infiltrate through leaking components in the wastewater system and originate from e.g., groundwater and leaking drinking-water distribution networks or enter as rainwater and surface water connected to the system, see e.g., [1]. Basement flooding, combined sewer overflows (CSOs), capacity problems, and unnecessary transport and wastewater treatment are among other adverse effects caused by I/I-water. I/I-water can be reduced by sewer rehabilitation measures, e.g., relining or chemical grouting, by measures to control the flows, e.g., separating combined systems or disconnecting private stormwater laterals from the sanitary sewer system, or by reducing the sources. Measures can also be performed to decrease the adverse effects of I/I-water after entering the system, e.g., increasing the capacity in the piping system and in the wastewater treatment plant (WWTP).

Due to challenges like climate change and the aging of existing wastewater systems it is increasingly important to maintain and renew the systems in an efficient way. As part of this process there is an enhanced need for decision support when choosing how to handle I/I. The cause-and-effect chain of I/I consists of numerous components due to the diverse palette of water sources causing various types of effects that are often not completely known. Negative effects can be reduced using different kinds of methods, all associated with uncertainties. Since uncertainty is inherent in many components affecting I/I, it is reasonable that these uncertainties are openly addressed, using a risk-based approach for 
supporting decisions on I/I-water reduction. Risk-based approaches have been suggested in similar contexts, e.g., by Haghighatafshar et al. [2], that argue that the conventional way of designing urban drainage infrastructure is problematic and do not account for the complexity of the systems.

The overall aim of this paper is to present a risk-based framework with important aspects to include in decision-support models for application on I/I to wastewater systems. The framework is based on established processes for risk assessment and decision support and aims to evaluate potential risk treatment options using a sustainability approach. Furthermore, previously published decision-support models on I/I are evaluated based on central criteria in the presented framework. It is identified how the models correspond to the suggested framework, and, based on this, what should be in focus in future studies.

\section{Materials and Methods}

\subsection{Developing the Framework}

The terminology and definitions by The International Organization for Standardization (ISO) [3] for the terms risk source, event, consequence, and risk treatment option are used in the framework presented here. ISO defines risk as an effect of the "uncertainty of objectives" and further notes that risk is usually expressed in terms of risk sources, potential events, their consequences, and their likelihood. The risk definition used by ISO is based on a traditional way of defining risk quantitatively, originally presented in work by Kaplan and Garrick [4]. This risk definition using events (also called scenarios), consequences, and likelihood (also called probability) has been developed by many to capture aspects relevant to different applications. Aven [5] argues that using probabilities to define risk is too narrow and that important aspects of uncertainty thus are excluded. The definition Risk $=(A, C, U)$ is therefore suggested by the author, where $A$ represents the events, $C$ the consequences, and $U$ the uncertainties. This is the risk definition used in the presented framework.

To account for uncertainties when assessing risk, a probabilistic approach can be used, see e.g., [6,7]. Instead of assigning deterministic values as input data, probability distributions are then used to represent possible intervals of the variables. Uncertainties are usually categorized as either aleatory or epistemic; aleatory uncertainties arise from randomness in samples, and epistemic uncertainties exist due to the lack of knowledge of a system. It is suggested that probability distributions are used as input data whenever possible when implementing the framework to represent aleatory and epistemic uncertainties. Uncertainty estimations can be based on both existing hard data and expert judgments. In situations with available data, relevant probability distributions can be identified using standard frequentist statistical methods. However, in situations of sparse data, Bayesian approaches and structured expert elicitation methods are today common practice, see e.g., [6-8]. Durbach and Stewart [9] provide an overview of methods to model uncertainties in MCDA.

Uncertainties are present throughout the risk chain of I/I (Figure 1). The risk chain starts with a source which may lead to events in the form of I/I and effects that result in corresponding consequences. In turn, the consequences result in the risk that is dependent on all previous steps in the risk chain.

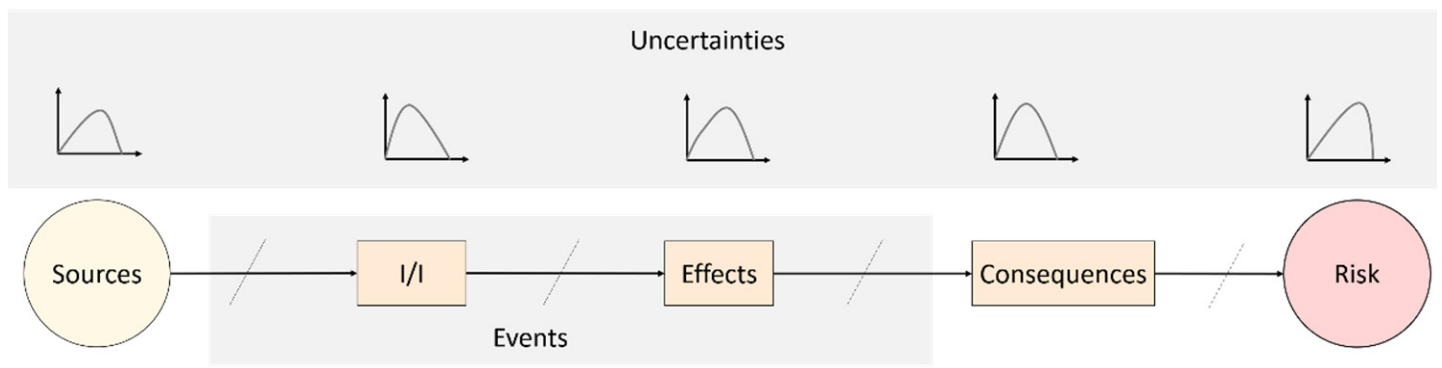

Figure 1. Risk chain of I/I illustrating the relationship of components defining risk in the framework. 
If a risk is too high, in accordance with existing objectives, risk criteria, available resources, and risk treatment options should be considered [3]. Deciding on the most appropriate treatment option involves taking various factors into consideration in a decisionmaking process. A suggestion of a basic structure for such a process is presented by Aven [7] (Figure 2). The point of departure is a decision problem and a set of decision alternatives. The results of the following risk analyses and decision analyses do not lead directly to a decision but provide decision support. The results are input to managerial review and judgement, which result in a decision or a revision of the decision alternatives. Boundary conditions for the whole decision-support process is set by stakeholder values, consisting of goals, criteria, and preferences including e.g., legal requirements. The structure of the presented framework was inspired by the decision-making process described by Aven [7].

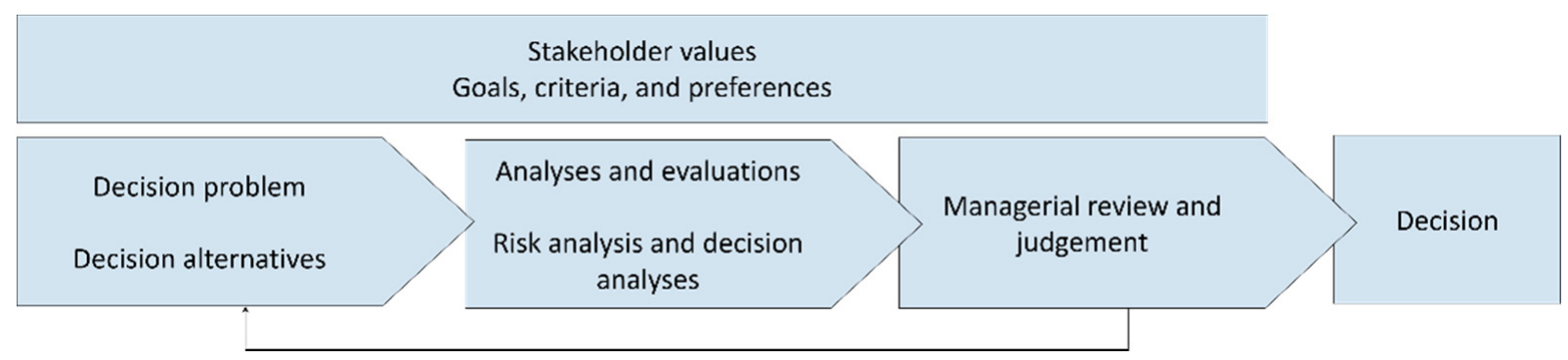

Figure 2. Decision-making process inspired by Aven [7].

Sustainability is commonly defined using the three dimensions of economic, social, and environmental sustainability, see e.g., [10]. It is argued that a development or action is not sustainable if it does not include all of these three dimensions. Several of the UN's sustainable development goals [11], e.g., Number 6: Clean water and sanitation and Number 11: Sustainable cities and communities, are connected to I/I. Hence, a broader perspective than the commonly used pure financial perspective is needed to include all aspects in society when assessing I/I. Since there are no established risk criteria on acceptable levels of I/I-water, the reasonable approach was to apply a sustainability perspective. Hence, the framework was developed based on the condition that economic, social, and environmental effects are equally important to include in the model.

\subsection{Ethical Principles and Decision Support Methods}

Decision-support methods are tools for aiding decision-making and can be based on different ethical theories. Consequentialism [12] is based on the ancient phrase and concept "the result justifies the deed". This means that an act is considered morally rightful only depending on the consequences of the act [13]. A common form of consequentialism is utilitarianism, which is based on the view that the alternative that gives the most total happiness to people should be chosen, see e.g., [14,15]. Hence, an anthropocentric perspective is applied, i.e., focus is put on human wellbeing. An example of a decisionsupport method based on the utilitarianism is cost-benefit analysis (CBA), which is often used by governments and private actors [16]. In a CBA, all costs and benefits resulting from proposed project alternatives are translated into monetary terms. The recommended alternative is the one where the sum of benefits exceeds the sum of costs the most.

Another ethical theory is the deontological [17], which focuses on duty and ethical values, rather than consequences [18]. In a sustainability context this means that, from a deontological perspective, decisions can be based on the duty of e.g., ensuring the welfare of future generations, see e.g., [19], or protecting the intrinsic value of wildlife or biodiversity [20]. A decision-support method that can be based on deontological theories is multicriteria decision analysis (MCDA). In a MCDA, the decision problem is divided into smaller parts that are evaluated separately before putting them together again, see e.g., [21]. Using scoring and weighting an overall picture can be obtained taking different criteria into consideration. 
The decision-support methods CBA and MCDA can relate to environmental, social, and economic effects in different ways (Table 1). A CBA should include all the environmental, social, and economic effects to society as a whole (CBA 1 in Table 1), see e.g., [22], but is sometimes in practice restricted to project internal financial effects (CBA 2 in Table 1). A MCDA could include financial, social, and environmental criteria (MDCA 1 in Table 1) or use the result from a CBA to provide input to the economic dimension (MDCA 2 in Table 1). In the last case, monetized environmental (i.e., monetized ecosystem services), social, and financial effects are considered to be part of the economic dimension, whereas social and environmental aspects including e.g., intrinsic values not monetized in the CBA can add other dimensions to the analysis.

Table 1. Examples of how the decision-support methods CBA and MCDA can relate the utilitarian and deontological ethical theories and to monetized and not-monetized economic, social, and environmental effects. Blue color represents the included dimensions.

\begin{tabular}{|c|c|c|c|c|c|}
\hline & & \multicolumn{4}{|c|}{ Ethical theory } \\
\hline \multirow{2}{*}{\multicolumn{2}{|c|}{ Effects }} & \multicolumn{2}{|c|}{ Utilitarian } & \multicolumn{2}{|c|}{ Deontological } \\
\hline & & CBA 1 & CBA 2 & MCDA 1 & MCDA 2 \\
\hline \multirow{3}{*}{ Monetized } & Environmental & & & & \\
\hline & Social & & & & \\
\hline & Financial & & & & \\
\hline \multirow{2}{*}{$\begin{array}{c}\text { Not } \\
\text { monetized }\end{array}$} & Social & & & & \\
\hline & Environmental & & & & \\
\hline
\end{tabular}

\subsection{Evaluating Models Based on Framework}

The evaluation of existing models was limited to models that clearly focus on decision support in relation to I/I. Based on central elements from the framework, a set of evaluation criteria were defined (Table 2).

Table 2. Evaluation criteria based on the presented framework.

\begin{tabular}{|c|c|}
\hline \multicolumn{2}{|c|}{ Evaluation Criteria } \\
\hline Risk-based & $\begin{array}{l}\text { Does the model include any quantification of risk using } \\
\text { conceptslike probability and consequence? }\end{array}$ \\
\hline Uncertainty & $\begin{array}{l}\text { Are uncertainties in input data considered, e.g., by assigning } \\
\text { probability distributions? }\end{array}$ \\
\hline \multicolumn{2}{|r|}{ P } \\
\hline Internal & Are any internal economic effects included in the model? \\
\hline External & Are any external economic effects included in the model? \\
\hline Social & Are any social effects included in the model? \\
\hline Environmental & Are any environmental effects included in the model? \\
\hline
\end{tabular}

Regarding sustainability, it was investigated if a model includes economic internal, economic external, social and/or environmental aspects and if these are monetized. A model was considered to include a dimension of sustainability if it includes one aspect of such kind, e.g., if the model includes one environmental aspect, it was considered to include environmental sustainability, even though other environmental aspects also exist and could have been included. Further, to be considered to include an aspect, the aspect had to be quantitatively or qualitatively included in the model, not just mentioned in the publication.

Models focusing on decision support and effects or risk treatment options that could relate to I/I, e.g., CSOs, rehabilitation, and building blue-green infrastructure were not included in the main evaluation. This, since there is no clear distinction on if, how, and to what extent these effects or risk treatment options relate to I/I. Including these models with a more vague connection to I/I in the main evaluation was therefore considered 
too extensive and outside the scope of this paper. However, some of the additional models are mentioned in a separate section of the result chapter, and it is discussed how these relate to the evaluation criteria based on the presented framework. It should be noted that this review does not try to cover all decision-support models that could relate directly or indirectly to I/I.

\section{Framework}

The initial part of the developed framework for decision support (Figure 3) consists of the identification of goals, criteria, and preferences. In this step, the system boundaries are set and objectives are determined. In the following risk analysis, the risk of I/I is estimated using events and their related consequences and uncertainties. Risk sources have the potential to trigger events of different magnitudes with some probability that include I/I and that lead to a sequence of effects that can be economic, social, and/or environmental and further, to consequences as illustrated in Figure 1. Uncertainties are present throughout this risk chain, and risk treatment options, or measures, can be implemented at each step to alter the magnitude of the events or their consequences. Further, the risk treatment options themselves can also result in effects with corresponding consequences. The steps of Goal, criteria, and preferences and Risk analysis are presented more in detail below.

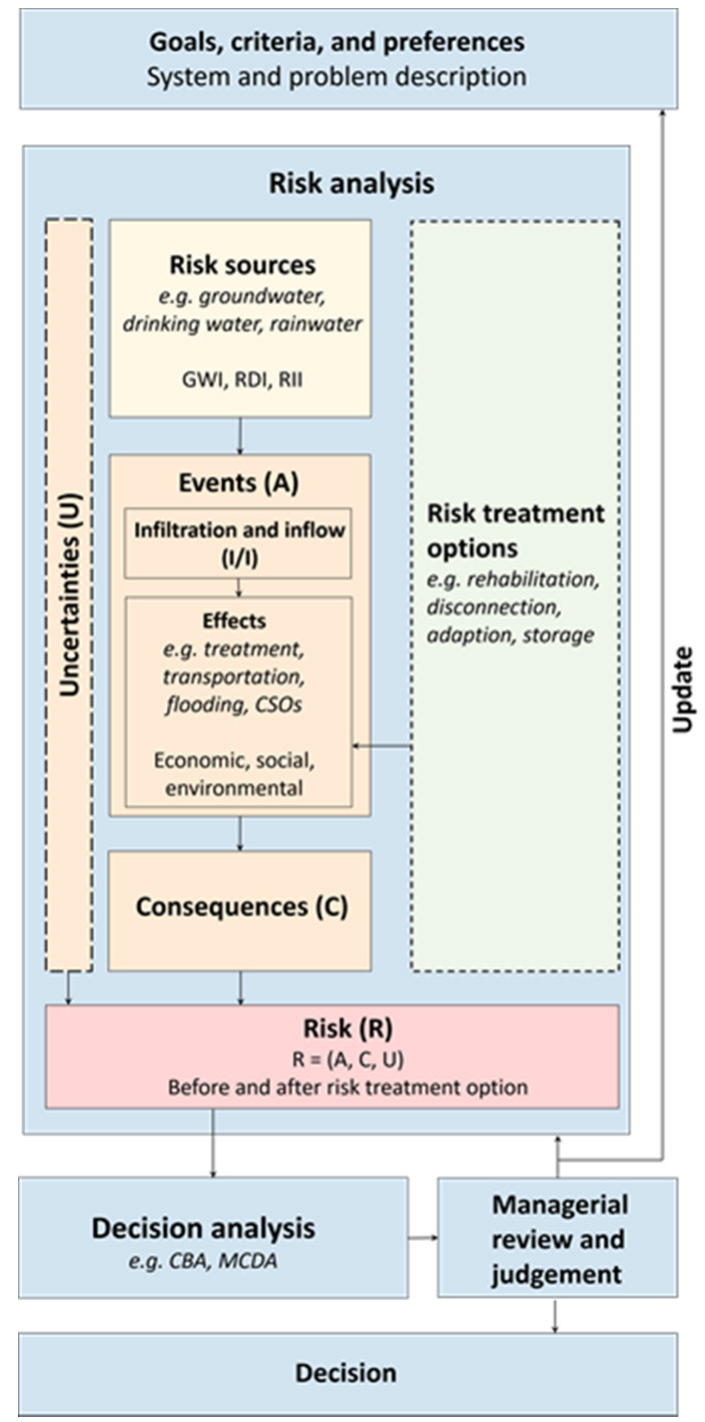

Figure 3. Suggested framework for risk-based decision support on I/I. 
When the risk of I/I has been estimated, the next step in the framework is to perform a decision analysis of alternative measures to reduce the risk. This can be done using different kinds of decision-support methods, e.g., CBA or MCDA. After obtaining a result from the decision analysis, the framework suggests a managerial review and judgement process that either leads to a revision of the result or a decision. The process is continuously updated when new information is available.

\subsection{Goals, Criteria, and Preferences}

In this initial step of the framework, the system and decision problem are described, which includes defining the system boundaries as well as deciding on objectives. How the system boundaries are set affects how I/I will be assessed in the further steps of the framework e.g., regarding which criteria are selected. A common approach when working with I/I is to focus either on the perspective of the wastewater piping network, the WWTP, or sometimes on both combined. However, broader system boundaries can also be used, including other parts of the society, the city, or even applying a global perspective (Figure 4). Examples of aspects that could be included or excluded depending on how the system boundaries are set are effects of I/I-water on private property owners, businesses, receiving waters, raw water sources, air quality, and global warming. Most important is to be aware that system boundaries always exist and that the result of an analysis will be dependent on how they are defined. Proper decision-making thus requires that system boundaries be carefully considered before a decision is made. From a sustainability perspective, it is recommended not to choose too narrow system boundaries since this may result in important events being excluded from the assessment. Moreover, the system boundaries also affect which stakeholders to include in the decision-making process.

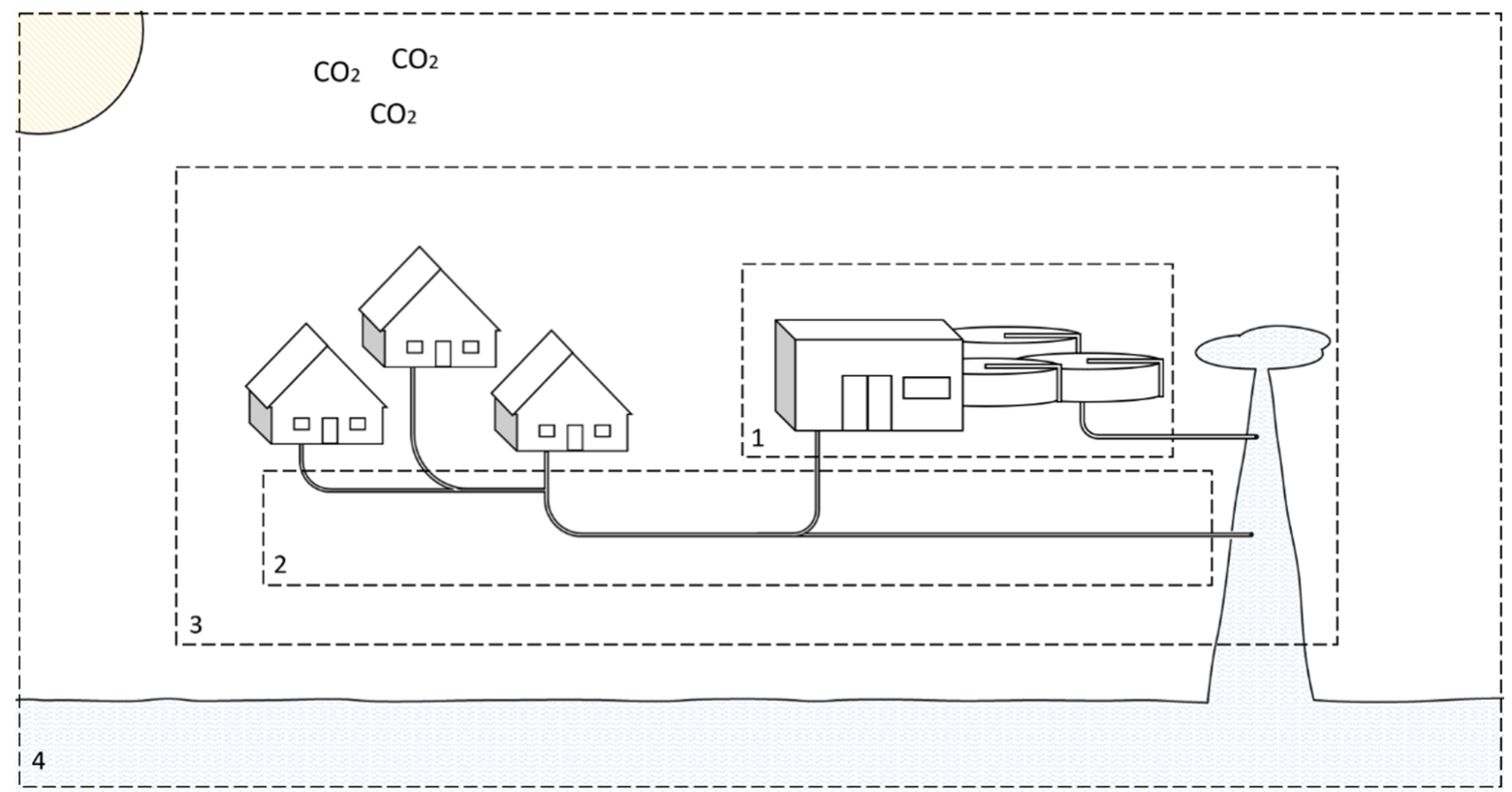

Figure 4. Examples of possible system boundaries (1: WWTP, 2: Piping system, 3: City, 4: Global).

Objectives are based on stakeholder values, legal requirements, and other criteria. The risks assessed further in the process will be evaluated based on how they affect the possibility of achieving these objectives. Objectives can aim for different parts of the risk chain of I/I. If aiming for the volume of I/I-water, an objective can be to decrease the I/I-water share of the total annual wastewater flow to a certain percentage. On the other hand, if aiming for the effects caused by I/I-water, an objective can be to not exceed a certain number of basement flooding events per year. Objectives can also be set up based on requirements from authorities and could then involve not exceeding a specific 
pollutant load in a water recipient. Other kinds of objectives could involve the optimization of the system, e.g., to implement risk treatment options at locations where the benefits exceed the costs. It is recommended that objectives be set relating rather to the effects caused by I/I-water than the I/I-water volume itself, see e.g., [23]. This is because it is not always given that volumes of I/I-water result in a problem, a fact that depends on the construction of the wastewater system and other factors. Setting objectives relating solely to the volume of I/I-water and not to its possible related effects can therefore result in suboptimal prioritizing.

\subsection{Risk Analysis}

The risk of I/I is a function of events and their subsequent effects and consequences, as well as all related uncertainties. Further, the events, effects, and consequences are interconnected, according to the risk chain (Figure 1). The chain starts with risk sources in the form of water with the potential to become I/I-water. Such sources are groundwater, water from leaking drinking-water pipes, rainwater, snowmelt, and surface water. The components can have different response times and be divided into groundwater infiltration (GWI), rain-induced infiltration (RII), and rain-derived inflow (RDI), a common division of I/I-water flows used by, e.g., Staufer et al. [24]. In case of the occurrence of I/I-water, various effects may follow, e.g., increased need for pumping and treatment, flooding, or CSOs. Focus is usually put on the negative effects of I/I-water but positive effects can also arise, e.g., controlled groundwater levels and decreased odor, see e.g., $[25,26]$.

Risk treatment options can be implemented at several locations in the risk chain of I/I. For example, a treatment option can aim at decreasing a risk source, e.g., by reducing leakage from drinking-water pipes. In Example 1 in Figure 5, the risk treatment option rehabilitation is suggested. Since rehabilitation means repairing, renovating, or replacing malfunctioning components, the risk treatment option is affecting how much water that can infiltrate the system and is located between the risk source step and infiltration step in the flowchart. Another treatment option could take place between the I/I step and the effect step, e.g., by building larger storage capacity to hinder CSOs from occurring. A risk treatment option can also be aiming to decrease the consequences given that an event has already occurred, e.g., building basements that can be allowed to occasionally be flooded.

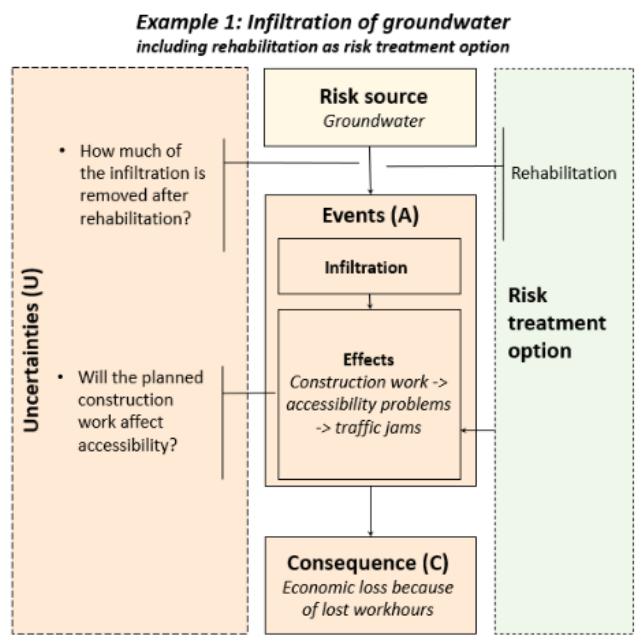

Example 2: Infiltration of leaking drinking water

Example 3: Inflow of rainwater
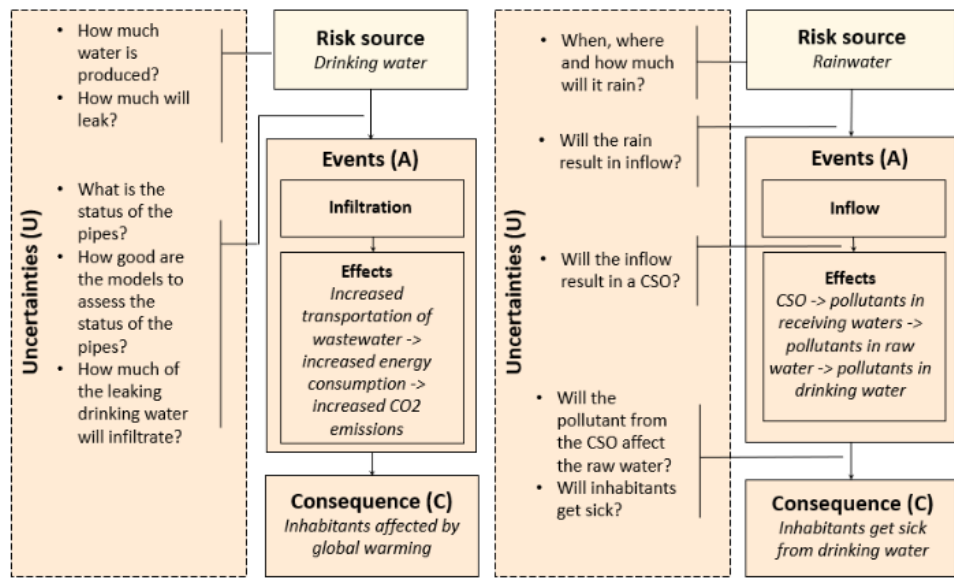

Risk (R)

$R=(A, C, U)$

Before and after risk treatment option

Figure 5. Examples of risk sources, events, and consequences with corresponding uncertainties. In the figure, the consequences are formulated from a utilitarian perspective, i.e., depending on how humans are affected.

Risk treatment options affect the risk chain and alter the magnitude of the risk. However, the risk treatment options in themselves also give rise to effects not corresponding 
to the original risk chain of I/I, which is illustrated by the arrow from the risk treatment option step to the effect step in Figure 3. These effects caused by the risk treatment options must also be included in the risk assessment. Examples of such effects are construction costs, emissions from construction works, and accessibility problems when performing rehabilitation. Positive effects can also arise, e.g., ecosystem benefits after building bluegreen stormwater infrastructure. The effects caused by the risk treatment options can be project internal or project external. Project-internal effects affect the project owner, e.g., the construction cost for a sewer department. Project-external effects are caused by the implementation of the project but do not directly affect the project owner, e.g., emissions from construction works and accessibility problems.

From a sustainability perspective, it must be recognized that events can result in economic, social, and environmental effects. In Figure 5, examples of risk chains leading to different kinds of effects are illustrated. In Example 1, rehabilitation of the pipe system to decrease the groundwater infiltration results in accessibility problems, which lead to economic losses due to traffic jams and lost workhours for the inhabitants. In Example 2, leaking drinking water results in increased transportation and the pumping of wastewater, leading to an environmental effect of increased $\mathrm{CO}_{2}$ emissions. In Example 3, rainwater results in CSOs, which lead to a social effect due to pollutants in the drinking water.

Uncertainties are present throughout the risk chain of I/I and can relate to various aspects (see examples of uncertainties in Figure 5). Aleatory uncertainties arise due to randomness in all transitions from risk sources to consequences in the risk chain but also from climate and weather changes. When performing risk assessment, regular and irregular changes in flows should be considered, e.g., daily changes in sanitary flows, as well as seasonal groundwater changes.

The knowledge of the state of the wastewater system tends to be limited since wastewater networks in general are large and situated underground, as well as difficult to monitor and reach. Factors that influence the state of the system are age, depth, material, and quality of the pipes and other components as well as geological surroundings, see e.g., $[1,27]$. Various methods and technologies exist to detect, localize, and quantify I/I-water including physical inspection, closed-circuit television (CCTV), tracer methods, flow-based methods, and sensors, see e.g., [28]. Utilizing these methods may decrease the epistemic uncertainties that arise due to limited knowledge of the system. Epistemic uncertainties may also arise because of the knowledge gap regarding the efficiency of risk treatment options, e.g., to what extent I/I-water is removed after a rehabilitation action. All uncertainties in the model should be represented by probability distributions.

\section{Evaluation of Models Based on the Framework}

\subsection{Models on I/I and Decision Support}

Eight models were found that focus on I/I and decision support. These have been assigned a letter from $\mathrm{A}$ to $\mathrm{H}$ and are described briefly below. The focus of each model is summarized in Table 3.

Table 3. Focus of evaluated models. A: Sola et al. [29], B: Davalos et al. [30], C: Diogo et al. [31], D: Moskwa et al. [32], E: Vallin [33], F: Lee et al. [34], G: King County [35], H: DeMonsabert and Thornton [36].

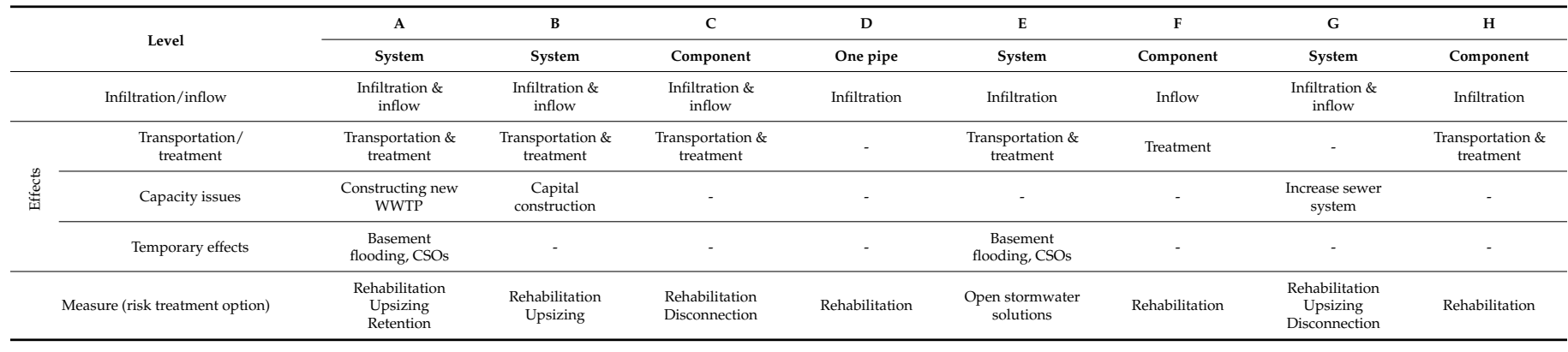


A. Sola et al. [29] presented a model for analyzing the consequences of I/I-water by comparing the four measures of full restoration of all wastewater pipes, increasing pump capacity, using local retention basins, and business as usual in the municipality of Asker in Norway. In the model, the costs of performing the different measures including operation costs are compared to the benefits of improved bathing-water quality and the avoidance of basement flooding.

B. Davalos et al. [30] presented a model to identify pumping stations in Miami-Dade County in the United States where it is more efficient to perform rehabilitation measures than to adapt the system to the I/I-water volumes. The costs of performing measures to reduce I/I-water based on historical data is compared to savings for not having to treat and transport the I/I-water, as well as savings for not constructing or oversizing WWTPs, pipes, or pumping stations due to I/I-water.

C. Diogo et al. [31] presented a model including two functions to optimize I/I-water reduction. In the first function, the costs for rehabilitation of each link and node, as well as costs for the removal of wrongly connected laterals in the sewer system, are compared to the savings of not having to transport and treat I/I-water. In the second function, the structural condition for each node and link in the system is included. By minimizing the functions, it can be determined if each node and link in the system should be rehabilitated or not, as well as which of the wrongly connected laterals should be removed. A case study is included using a simplified approach at three locations in Coimbra, Portugal.

D. Moskwa et al. [32] presented a model to evaluate four different rehabilitation measures to reduce infiltration in a large trunk sewer in the region of Halton, California, United States. Eight different evaluation criteria, e.g., cost, infiltration elimination, and local availability are set up. For each rehabilitation measure, scores are assigned, and, after including weighing for the evaluation criteria, a total score for each rehabilitation measure can be obtained.

E. Vallin [33] presented a model aiming to examine the suitability of using multicriteria analysis for the spatial resource allocation of stormwater solutions in order to reduce inflow. In the model, all properties and hard surfaces in an area are assigned a score symbolizing their need for improvement based on the risk of large volumes of I/I-water, basement flooding, and CSOs. The properties and hard surfaces are merged into sub-areas and their scores compared to the cost of performing a measure to reduce the inflow. Hence, the sub-areas where it is most efficient to perform a measure can be identified. A case study using the model in Bjurås in Sweden is included.

F. Lee et al. [34] presented a model aiming to facilitate decisions on which order the wastewater system in subareas should be rehabilitated to minimize I/I-water to the WWTP during the rehabilitation process. Based on detected defects on each pipe in the system, the volume of I/I-water in the subareas was estimated. In the following step, the optimal rehabilitation order was determined. A case study was performed in Seoul, South Korea.

G. King County [35] presented a model aiming to identify cost-effective I/I-water reduction projects in King County, Washington, United States. The county identified system improvements that were required to manage the projected future flows. The costs of these projects were then compared to the cost of performing I/I measures, e.g., the disconnection of public and private laterals and rehabilitation. In those cases where the I/I measure in a subarea resulted in reaching the targets and the cost of performing the measure was below the cost of the conveyance system improvement, the I/I measure was recommended.

H. DeMonsabert and Thornton [36] presented a model aiming to find the most effective method of repair for each defected manhole or pipe in a system. An equation was set up including possible repairs within the system for each component, as well as the change of I/I-water and the cost of treating I/I-water. The equation was then 
minimized to determine which method, if any, was most efficient to use for each component. A case study was carried out in Washington, DC, United States.

The result of the evaluation of the models based on the decision criteria is presented in Table 4 and further explained below.

Table 4. Evaluation of models based on framework. A: Sola et al. [29], B: Davalos et al. [30], C: Diogo et al. [31], D: Moskwa et al. [32], E: Vallin [33], F: Lee et al. [34], G: King County [35], H: DeMonsabert and Thornton [36].

\begin{tabular}{|c|c|c|c|c|c|c|c|c|}
\hline Evaluation Criterion & A & B & $\mathrm{C}$ & $\mathbf{D}$ & $\mathbf{E}$ & $F$ & $G$ & $\mathbf{H}$ \\
\hline Risk-based & & & & & $\checkmark$ & & & \\
\hline Uncertainty & & & & & $\checkmark$ & & $(\checkmark)$ & \\
\hline \multicolumn{9}{|l|}{ Sustainability } \\
\hline \multicolumn{9}{|l|}{ Economic } \\
\hline Internal & $€$ & $€$ & $€$ & $\checkmark$ & $€$ & $€$ & $€$ & $€$ \\
\hline External & $€$ & & & & & & & \\
\hline Social & $€$ & & & & $\checkmark$ & & & \\
\hline Environmental & $€$ & & & & $\checkmark$ & & & \\
\hline
\end{tabular}

Among the models, only Model E uses a risk-based approach. This is done by assigning probability and consequence scores to the different effects included in the model. Model E also includes uncertainty in the analysis by assigning intervals to the data fed into the model. Method $\mathrm{G}$ includes uncertainty to some extent by performing a sensitivity analysis making some of the initial assumptions more conservative. None of the other methods include uncertainty in their analyses.

When it comes to the included effects by I/I, most of the models only include internal economic factors. Models B, C, and $\mathrm{H}$ include internal economic effects by using costs for performing the measures, as well as the cost for treating and transporting I/I-water. Models D and G include the internal economic effects by using the cost for performing the measures. Model $\mathrm{F}$ includes the internal economic effects by including the wastewater treatment cost. Among these models, models B, D, F, G, and H express the internal economic effects in monetary terms by using the actual financial cost for the measure, transportation, or treatment. In model C, the costs for the measures are not monetized but are assessed in a three-point graded scale.

Models $\mathrm{A}$ and $\mathrm{E}$ differ from the other models by including more effects than the internal economic. Model A includes both internal and external economic effects. The internal economic effects are included by using the cost of performing the measures evaluated in the study as well as operating costs. Further, the external economic effects are included by the monetization of social and environmental effects. The social effects are represented by the households' willingness to pay for avoiding basement flooding. Environmental effects are represented by the willingness to pay for improved water quality, also including improved fishing conditions and bathing-water quality. Model E includes internal economic effects by using the cost for performing the measures. Social effects are included by evaluating the consequence of basement flooding, considering the number of residents per property. Environmental effects are considered by including the consequence of CSOs, taking factors like the ecological and chemical state of the receiving water into account. The social and environmental effects are not monetized in this model but receive a score depending on the estimated severity of their consequences.

None of the publications, including the evaluated models, declare what ethical theory was used as a basis for the analyses. However, the models are considered to be based on a utilitarian perspective when the option with the highest benefits in relation to the costs is chosen. In six of the eight evaluated models, these costs and benefits consist only of the internal financial cost of implementing a measure compared to the internal financial cost of transporting and treating the I/I-water that would be removed by the measure. 


\subsection{Examples of Other Models with a Broader Scope}

Many decision-support models related to I/I have been identified in the literature, but most have a broader scope compared to the focus of this paper. In this section a few models and how they are related to the presented framework are mentioned.

With regards to general decision-support tools for wastewater systems, an overview of some models has been presented by Rehan et al. [37]. Additionally, a vast number of models exists regarding risk-based decision-making for pipe renewal. The risk of failure is usually estimated by determining the likelihood and consequences of the failure of a pipe, see e.g., [38,39]. The existing models include, to various extents, economic, social, and environmental aspects as well as uncertainty. Vladeanu and Matthews [40] provide an overview, as well as a comparison of some of the models used in trenchless renewal decision-making.

Korving et al. [41] present a model focusing on decision support and CSOs. The model is risk-based and presents an approach for the economic optimization of in-sewer storage. In the model, uncertainties are included, e.g., when it comes to variability in rainfall, sewer system dimensions, and environmental damage. The environmental cost of CSOs is based on willingness-to-pay studies. Dusenbury et al. [42] present a model on decision support regarding implementing green infrastructure in order to reduce CSOs. A scorecard is developed to evaluate the measures based on various decision criteria. Economic, social, and environmental aspects are all represented in the categories hydraulic benefit/cost ratio, co-benefits, feasibility, and sustainability. The model is, however, not risk-based, and uncertainties are not included. Another example of a model focusing on decision support, CSOs, and green infrastructure is presented by Alves et al. [43]. This method is not risk-based and does not include uncertainties.

In their model, Casal-Campos et al. [44] evaluate three gray and three green drainage strategies using economic, social, and environmental impact categories, e.g., capital cost, health and aesthetics, and greenhouse gas emissions. They account for uncertainties by evaluating the drainage strategies in four future scenarios connected to markets, innovation, austerity, and lifestyles. A similar, developed and more strategic model is presented by Sadr et al. [45], wherein future green and gray strategies are compared using a MCDA approach. The compared strategies are evaluated based on their compliance regarding adaption thresholds for sewer flooding, river flooding, and CSOs and include economic, social, and environmental aspects. These models are not risk-based but include uncertainty to some extent.

Additionally, a model by Beheshti and Sægrov [46] compare different strategies for management for wastewater systems based on sustainability indicators, e.g., greenhouse gases, treated wastewater, and operation and maintenance expenses per capita. Reduction of I/I-water is in this model one of the four compared strategies.

Several of the mentioned models fulfill some of the criteria in the presented framework and contain good approaches of how to handle aspects related to I/I in a decision-making context. However, to achieve an effective treatment of I/I a model aiming for the holistic $\mathrm{I} / \mathrm{I}$ problem, as well as including all criteria in the presented framework is recommended.

\section{Conclusions}

Today's wastewater systems are enormous infrastructure assets in need of maintenance and development. Due to large costs and finite resources in society, there is a need for decision support to improve the systems in the most efficient way from a sustainability and thus also socio-economic perspective. The major conclusions drawn from this study are:

- This paper presents a novel framework for risk-based decision support for handling infiltration and inflow (I/I) to wastewater systems based on established concepts, e.g., definitions by ISO [3], and the decision-making process described by Aven [7]. Fundamental features of the framework are (1) the assessment of the risk of I/I by taking into account the complete chain from the source of I/I to the resulting effects and consequences, using events, consequences, and uncertainties; and (2) taking the 
three dimensions of sustainability, i.e., economic, social, and environmental aspects, into account.

- Among the eight published and reviewed existing models on I/I and decision support, none fully fulfil the evaluation criteria based on the presented framework. Only one of the models uses a risk-based approach, and two include uncertainties to any extent. Further, most of the models only include project internal economic effects, excluding the social and environmental dimensions of sustainability.

- Future research on implementing the framework, e.g., when performing a CBA or MCDA, is suggested, as well as a deeper analysis on how the system boundaries affect the assessed risk of I/I. More research is also needed on the behavior of I/Iwater and potential risk treatment options in the wastewater systems to decrease epistemic uncertainties.

Author Contributions: Conceptualization, A.O.S., L.R. and A.L.; methodology, A.O.S., L.R. and A.L.; writing—original draft preparation, A.O.S.; writing—review and editing, A.O.S., L.R. and A.L.; visualization, A.O.S.; supervision, L.R. and A.L.; funding acquisition, L.R. and A.L. All authors have read and agreed to the published version of the manuscript.

Funding: This paper was produced as part of the Mistra InfraMaint research program with funding from the Department for Sustainable Waste and Water in the City of Gothenburg, Mistra, the Swedish Foundation for Strategic Environmental Research and Swedish Water \& Wastewater Association.

Institutional Review Board Statement: Not applicable.

Informed Consent Statement: Not applicable.

Data Availability Statement: Data are available upon reasonable request to the corresponding author.

Conflicts of Interest: The authors declare no conflict of interest.

\section{References}

1. USEPA. Control of Infiltration and Inflow into Sewer Systems; Environmental Protection Agency, Water Quality Office: Washington, DC, USA, 1970.

2. Haghighatafshar, S.; Becker, P.; Moddemeyer, S.; Persson, A.; Sörensen, J.; Aspegren, H.; Jönsson, K. Paradigm shift in engineering of pluvial floods: From historical recurrence intervals to risk-based design for an uncertain future. Sustain. Cities Soc. 2020, 61, 102317. [CrossRef]

3. ISO. Risk Management-Guidelines ISO 31000:2018; International Organization for Standardization: Geneva, Switzerland, 2018.

4. Kaplan, S.; Garrick, B.J. On The Quantitative Definition of Risk. Risk Anal. 1981, 1, 11-27. [CrossRef]

5. Aven, T. On how to define, understand and describe risk. Reliab. Eng. Syst. Saf. 2010, 95, 623-631. [CrossRef]

6. Bedford, T.; Cooke, R. Probabilistic Risk Analysis: Foundations and methods; Cambridge University Press: Cambridge, UK, 2001.

7. Aven, T. Foundations of Risk Analysis: Second Edition; John Wiley \& Sons: Hoboken, NJ, USA, 2012.

8. O'Hagan, A. Expert knowledge elicitation: Subjective but scientific. Am. Stat. 2019, 73 (Suppl. 1), 69-81. [CrossRef]

9. Durbach, I.N.; Stewart, T.J. Modeling uncertainty in multi-criteria decision analysis. Eur. J. Oper. Res. 2012, 223, 1-14. [CrossRef]

10. UN General Assembly. Resolution adopted by the General Assembly on 16 September 2005. 2005 World Summit Outcome. 2005. Available online: https://www.un.org/ga/search/view_doc.asp?symbol=A/RES/60/1\&Lang=E (accessed on 16 September 2020).

11. UN General Assembly Transforming Our World: The 2030 Agenda for Sustainable Development. Available online: https: //www.refworld.org/docid/57b6e3e44.html (accessed on 17 December 2020).

12. Anscombe, G.E.M. Modern moral philosophy. Philosophy 1958, 33, 1-19. [CrossRef]

13. Sinnott-Armstrong, W. Consequentialism. In The Stanford Encyclopedia of Philosophy (Summer 2019 Edition); Zalta, E.N., Ed.; Available online: https://plato.stanford.edu/archives/sum2019/entries/consequentialism (accessed on 25 February 2021).

14. Bentham, J. An Introduction to the Principles of Morals and Legislation; Oxford Clarendon Press: Oxford, UK, 1789.

15. Mill, J.S. Utilitarianism, 1863 Reprinted in Marshall Cohen (ed.); The Philosophy of John Stuart Mill; Modern Library: New York, NY, USA, 1961; pp. 321-398.

16. McFarland, M.S. Occidental Engineering Case Study: Part 1; Markkula Center for Applied Ethics. 2012. Available online: https://www.scu.edu/ethics/focus-areas/more/engineering-ethics/engineering-ethics-cases/occidental-engineering-casestudy-part-5/ (accessed on 25 February 2020).

17. Broad, C.D. Five Types of Ethical Theory; Routhledge \& Kegan Paul: London, UK, 1930.

18. Kant, I. Groundwork of the Metaphysics of Morals; tr. H. Paton. Harper \& Row: New York, NY, USA, 1948.

19. Howarth, R.B. Sustainability under uncertainty: A deontological approach. Land Econ. 1995, 1, 417-427. [CrossRef] 
20. Spash, C.L. Ethics and Environmental Attitudes With Implications for Economic Valuation. J. Environ. Manag. 1997, 50, 403-416. [CrossRef]

21. DCLG. Multi-Criteria Analysis: A Manual; Department for Communities and Local Government: London, UK, 2009. Available online: https://assets.publishing.service.gov.uk/government/uploads/system/uploads/attachment_data/file/7612/1132618 .pdf (accessed on 16 February 2021).

22. Boardman, A.E.; Greenberg, D.H.; Vining, A.R.; Weimer, D.L. Cost-Benefit Analysis: Concepts and Practice; Cambridge University Press: Cambridge, UK, 2017.

23. Bäckman, H.; Hellström, B.G.; Jaryd, A.; Jonsson, Å. Measures to Minimize the Influence of Infiltration and Drainage in Sewerage Systems; VAV AB: Stockholm, Sweden, 1997. (In Swedish)

24. Staufer, P.; Scheidegger, A.; Rieckermann, J. Assessing the performance of sewer rehabilitation on the reduction of infiltration and inflow. Water Res. 2012, 46, 5185-5196. [CrossRef]

25. Gustafsson, L.-G. In Alternative Drainage Schemes for Reduction of Inflow/Infiltration-Prediction and Follow-up of Effects with the Aid of an Integrated Sewer/Aquifer Model. In Proceedings of the 1st International Conference on Urban Drainage via Internet, Niagara Falls, ON, Canada, 12-17 September 2000; pp. 21-37.

26. Marleni, N.; Gray, S.; Sharma, A.; Burn, S.; Muttil, N. Impact of water management practice scenarios on wastewater flow and contaminant concentration. J. Environ. Manag. 2015, 151, 461-471. [CrossRef]

27. Bäckman, H. Infiltration/Inflow in Separate Sewer Systems: Some Aspects on Sources and a Methodology for Localization and Quantification of Infiltration into Sanitary Sewers Caused by Leaking Storm Sewers. Ph.D. Thesis, Chalmers University of Technology, Gothenburg, Sweden, 1985.

28. Beheshti, M.; Saegrov, S.; Ugarelli, R. Infiltration/Inflow Assessment and Detection in Urban Sewer System. VANN 2015, 1, 24-34.

29. Sola, K.J.; Bjerkholt, J.T.; Lindholm, O.G.; Ratnaweera, H. Analysing consequences of infiltration and inflow water (I/I-water) using cost-benefit analyses. Water Sci. Technol. 2020, 82, 1312-1326. [CrossRef]

30. Davalos, P.; Humphrey, G.; Eagle, S.; Roque, R.; Bedoya, J.; Edwards, D.; Torrealba, F.; Perez, J.; Dvorak, A. Cost Effective Infiltration and Inflow Analysis and Remediation Efforts in Miami-Dade County. In Proceedings of the 91st Annual Water Environment Federation Technical Exhibition and Conference (WEFTEC), New Orleans, LA, USA, 29 September-3 October 2018; pp. 2994-3023.

31. Diogo, A.F.; Barros, L.T.; Santos, J.; Temido, J.S. An effective and comprehensive model for optimal rehabilitation of separate sanitary sewer systems. Sci. Total Environ. 2018, 612, 1042-1057. [CrossRef]

32. Moskwa, P.; Filipovic, J.; Latimer, N.; Bainbridge, K. Eliminating Sewer Infiltration within the Region of Halton. In Proceedings of the NASTT's 2018 No-Dig Show, Palm Springs, CA, USA, 25-29 March 2018.

33. Vallin, H. Evaluation of Multi Criteria Analysis as a Tool for Spatial Resource Allocation of Stormwater Measures for Inflow and Infiltration to the Sewage Water System. Master's Thesis, Uppsala University, Uppsala, Sweden, 2016. (In Swedish).

34. Lee, J.H.; Baek, C.W.; Kim, J.H.; Jun, H.D.; Jo, D.J. Development of a Decision Making Support System for Efficient Rehabilitation of Sewer Systems. Water Resour Manag. 2009, 23, 1725-1742. [CrossRef]

35. King County. Benefit/Cost Analysis Report-Regional Infiltration and Inflow Control Program; Department of Natural Resources and Parks: Seattle, WA, USA, 2005.

36. DeMonsabert, S.; Thornton, P. A benders decomposition model for sewer rehabilitation planning for infiltration and inflow planning. Water Environ. Res. 1997, 69, 162-167. [CrossRef]

37. Rehan, R.; Knight, M.A.; Unger, A.J.A.; Haas, C.T. Financially sustainable management strategies for urban wastewater collection infrastructure-development of a system dynamics model. Tunn. Undergr. Space Technol. 2014, 39, 116-129. [CrossRef]

38. Baah, K.; Dubey, B.; Harvey, R.; McBean, E. A risk-based approach to sanitary sewer pipe asset management. Sci. Total Environ. 2015, 505, 1011-1017. [CrossRef]

39. Vladeanu, G.J. Wastewater Pipe Condition and Deterioration Modeling for Risk-Based Decision-Making. Ph.D. Thesis, Lousiana Tech University, LA, USA, 16 August 2018.

40. Vladeanu, G.; Matthews, J.C. Analysis of risk management methods used in trenchless renewal decision making. Tunn. Undergr. Space Technol. 2018, 72, 272-280. [CrossRef]

41. Korving, H.; Van Noortwijk, J.M.; Van Gelder, P.H.A.J.M.; Clemens, F.H.L.R. Risk-based design of sewer system rehabilitation. Struct. Infrastruct. Eng. 2009, 5, 215-227. [CrossRef]

42. Dusenbury, R.; Zickler, E.; Phillips, J.; Lancaster, A. A Paper on Balancing CSO Program Investment: The King County Green Infrastructure Scorecard. In Proceedings of the 91st Annual Water Environment Federation Technical Exhibition and Conference (WEFTEC), New Orleans, LA, USA, 29 September-3 October 2018; pp. 4817-4835.

43. Alves, A.; Sanchez, A.; Vojinovic, Z.; Seyoum, S.; Babel, M.; Brdjanovic, D. Evolutionary and holistic assessment of green-grey infrastructure for CSO reduction. Water 2016, 8, 402. [CrossRef]

44. Casal-Campos, A.; Fu, G.; Butler, D.; Moore, A. An Integrated Environmental Assessment of Green and Gray Infrastructure Strategies for Robust Decision Making. Environ. Sci. Technol. 2015, 49, 8307-8314. [CrossRef] [PubMed]

45. Sadr, S.M.K.; Casal-Campos, A.; Fu, G.; Farmani, R.; Ward, S.; Butler, D. Strategic planning of the integrated urban wastewater system using adaptation pathways. Water Res. 2020, 182, 116013. [CrossRef] [PubMed]

46. Beheshti, M.; Sægrov, S. Sustainability assessment in strategic management of wastewater transport system: A case study in Trondheim, Norway. Urban Water J. 2018, 15, 1-8. [CrossRef] 